\section{Hyperacute fatal course in a}

\section{hypercalcemic crisis}

\section{Sara Turco ${ }^{1 *}$, Alice Chiara Manetti ${ }^{1}$, Aniello Maiese ${ }^{1}$, Matteo Scopetti ${ }^{2}$ and Marco Di Paolo ${ }^{1}$}

'Section of Legal Medicine, Department of Surgical, Medical, Molecular Pathology and Critical Area, University of Pisa, Pisa, Italy

${ }^{2}$ Department of Anatomical, Histological, Forensic and Orthopedic Sciences (SAIMLAL), Sapienza

University of Rome, Roma, Italy

A 39-year-old woman, with a not significant past medical history, entered the Emergency Department complaining about nausea, vomiting, constipation, anorexia, deep asthenia, and diffuse muscle aches with cramps. She referred sporadic diarrhea (one episode) the day before and a worsening headache in the past three days; she also complained about polyuria and polydipsia not investigated for one year. The clinical examination was not significant, apart from the evidence of skin and mucosal dryness, tachycardia, and diffuse abdominal pain. The laboratory tests revealed hypokalemia and elevated beta-human chorionic gonadotropin ( $\beta$-hCG) plasma levels. An ultrasound abdominal imaging was consistent with kidney lithiasis. Suspecting a hyperemesis gravidarum in a patient with kidney lithiasis, a rehydrating therapy was administered as long as potassium reintegration. During the hospital stay, the patient became drowsy. A haemogasanalysis revealed very high calcium values: 3,379 $\mathrm{mmol} / \mathrm{L}$ (n.v. 1,120-1,320 mmol/L). Lab tests confirmed very high levels of calcium 21,1 mg/dL (n.v. 9-10,5 mg/dL), as long as increased parathormone (PTH) $>3000 \mathrm{pg} / \mathrm{mL}$ (normal values $14-65 \mathrm{pg} / \mathrm{mL}$ ), and hypokalemia $(3,2 \mathrm{mEq} / \mathrm{L}$ n.v. 3,50 $-4,50$ ). Ultrasound exam of the neck revealed the presence of a left parathyroid nodule measuring 2,5 x 1,6 cm. Before having time to start an appropriate therapy, the patient died.

The autoptic examination revealed lung edema and a "shock aspect" of the kidney. The left inferior parathyroid had a nodule, the size of $4 \times 2 \times 1.5 \mathrm{~cm}$, with hemorrhagic aspect.

The kidney histology revealed severe nephrolithiasis and nephrocalcinosis (Figure $1 \mathrm{~A}, \mathrm{~B}$ ). The parathyroid histology was consistent with a diagnosis of atypical adenoma, with neoplastic embolism of periglandular vessels (Figure 2). Heart samples revealed contraction band necrosis (Figure 3). Von Kossa stain, specifically used to illustrate calcium and potassium, was intensively positive in kidney samples (Figure $1 \mathrm{C}, \mathrm{D}$ ).

\author{
More Information \\ *Address for Correspondence: Sara Turco, \\ MD, Department of Surgical, Medical, Molecular \\ Pathology and Critical Area, Section of Legal \\ Medicine, University of Pisa, Italy, \\ Tel: +393498682006; \\ Email: turco_sara@libero.it \\ Submitted: January 18, 2021 \\ Approved: January 19, 2021 \\ Published: January 20, 2021 \\ How to cite this article: Turco S, Manetti AC, \\ Maiese A, Scopetti M, Di Paolo M. Hyperacute \\ fatal course in a hypercalcemic crisis. J Clini \\ Nephrol. 2021; 5: 008-009 \\ DOI: 10.29328/journal.jcn.1001066 \\ Copyright: () 2021 Turco S, et al. This is \\ an open access article distributed under the \\ Creative Commons Attribution License, which \\ permits unrestricted use, distribution, and \\ reproduction in any medium, provided the \\ original work is properly cited. \\ Check for updates \\ OPEN ACCESS
}

Hypercalcemic crisis (serum calcium $>15-18 \mathrm{mg} / \mathrm{dL}$ ) is a medical emergency, with potentially severe cardiac and renal consequences. The therapy is based on rehydration, according to serum calcium values, general condition of the patient, and comorbidities. In case of renal insufficiency, dialysis is mandatory for calcium excretion [1,2]. Early diagnosis and adequate treatment with hemodialysis can rapidly improve patient consciousness and prevent fatal complications [1].
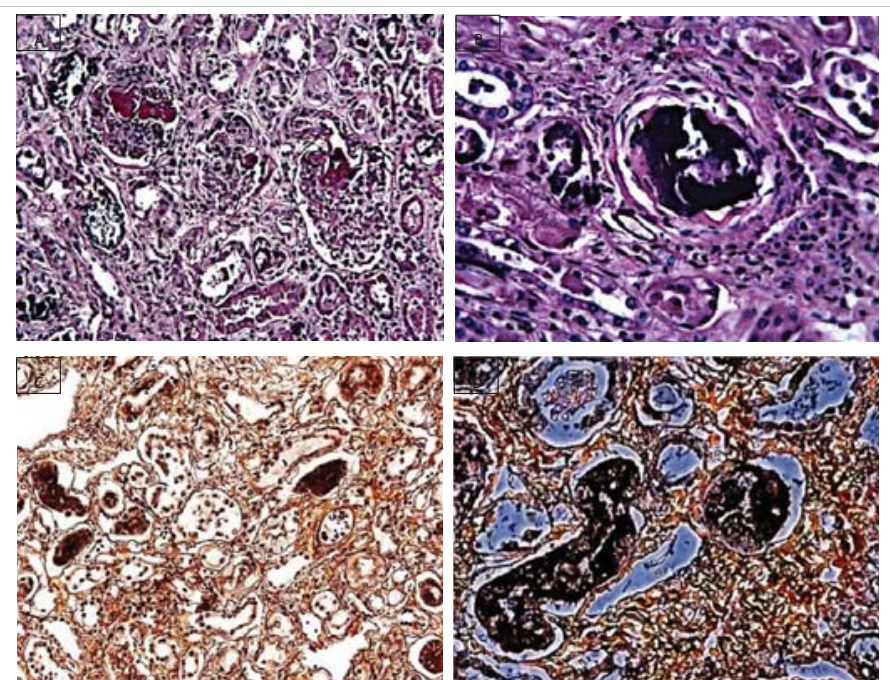

Figure 1: Histological examination of the kidney: H\&E stain revealed an accumulation of an amorphous slightly crystalloid basophilic irregular mass, consistent with calcification (A - magnification 20X, B - magnification 40X); von Kossa stain showed positive black stain within the calcification $(\mathrm{C}$ - magnification 10X, D - magnification 40X). 


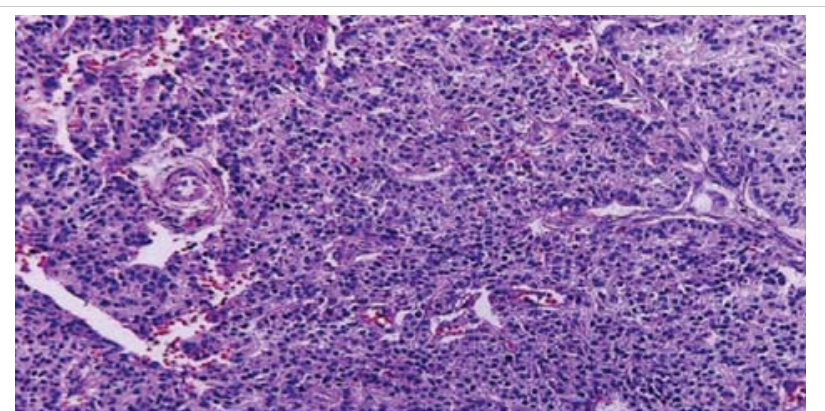

Figure 2: Histological examination of the parathyroid gland (H\&E, magnification 10X): monomorphic cell proliferation (hypercellularity) delimitated by a fibrous capsule with septa. The diagnosis was consistent with atypical adenoma.

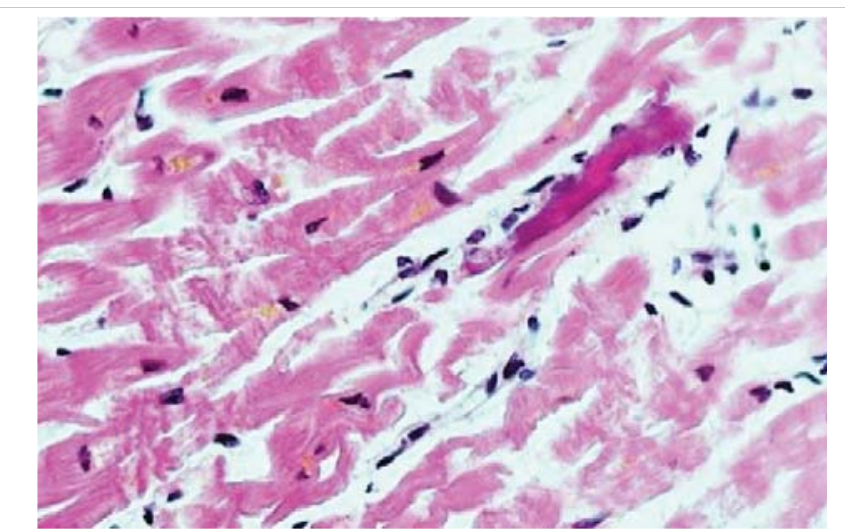

Figure 3: Histological examination of the heart (H\&E, magnification 20X): diffuse and massive contraction band necrosis.
Death could occur due to the high serum calcium concentration in the extracellular fluid of the myocytes, inducing QT shortening and cardiac arrhythmia [3]. Calcium values $>18 \mathrm{mg} / \mathrm{dL}$ can induce renal failure, shock and death [3].

Clinical manifestations are usually not specific, making the diagnosis of hypercalcemic crisis troublesome $[1,2]$. Hypercalcemic crisis is an insidious clinical condition, mostly resulting from hyperparathyroidism that can suddenly deteriorate to death. As it is easily reversible with a prompt therapy, serum calcium evaluation should be mandatory to avoid the omission of this rare but potentially fatal complication.

\section{References}

1. Wang CC, Chen YC, Shiang JC, Lin SH, Chu P, et al. Hypercalcemic crisis successfully treated with prompt calcium-free hemodialysis. Am J Emerg Med. 2009; 27: 1174.e1-3.

PubMed: https://pubmed.ncbi.nlm.nih.gov/19931789/

2. Ahmad S, Kuraganti G, Steenkamp D. Hypercalcemic crisis: a clinical review. Am J Med. 2015; 128: 239-245.

PubMed: https://pubmed.ncbi.nlm.nih.gov/25447624/

3. Porter RS, Kaplan JL. Chapter 97. Fluid and Electrolyte Metabolism'. The Merck manual of diagnosis and therapy (19th ed.). 2011; 949-986. 